\title{
RELAXATION - CONSCIOUS INHIBITION
}

\author{
By MARY PHILLIPS, M.C.S.P. \\ Dept. of Physical Medicine, St. Thomas' Hospital, London.
}

$\mathbf{T}^{\mathrm{T}}$ HE term "Conscious Inhibition" may at first appear to bear no relationship to relaxation; even the meaning by itself requires mental exercise before it is clearly understood in this context.

To many, relaxation is a simple matter in the absence of disturbance, and when the surroundings are such that the quietness, the absence of bright lighting and a comfortable temperature, produce a feeling of ease and comfort. There is then nothing to stimulate mental or physical effort. Add to this a normal degree of fatigue after a day's work, together with a feeling of satisfaction for its achievements and a plan of action for the morrow. The result is a mind and body tuned for complete and refreshing relaxation.

Types of Patient.

The physiotherapist is frequently called upon to give relaxation exercises to patients who have developed an habitual state of tension, and who are unable to bring about a reversal which would enable them to recuperate from the effects of constant mental and physical activity. They sleep badly. They suffer from physical aches and pains and they are impatient and irritable. Also included in this group are the sufferers of chronic illnesses, as, for example, asthmatics and chronic bronchitics and patients who are the victims of chronic arthritis, and there are many others. Expectant mothers form a group of their own. For them, relaxation exercises are a preparation for active participation and maintaining self-control under conditions of considerable stress at the time of their confinement.

Training in Relaxation.

At the outset it is important for the physiotherapist to face the fact that training in relaxation may take a long time. Patients who need this treatment possess a continual and abnormal amount of activity of their muscles. There is no pathological lesion of the anatomical systems invloved. They have simply to learn to rest their muscles, to reduce activity of them to a lower level. This is the argument against the contrast method of teaching relaxation, which emphasises tightening and letting go, but fails to impress upon the patient his need to relax from his habitulal hypertonic resting position.

Muscle Relaxation.

A planned course of relaxation therapy should begin with a clear and simple explanation to the patient of the meaning of muscle relaxation. The first essential that he must grasp is that it involves more than just assuming a fully supported position under ideal conditions. A dog lying in its basket, but evidently on the alert having been disturbed by the noise of footsteps outside or a distant bark of another dog, may be lying completely supported, but its muscles are in a state of readiness, of having "taken up the slack." The eyes are wide open and the head almost raised, while the respiratory movements are increased in rate. A completely different picture is that of a cat lying on the hearth, not necessarily asleep, but with limbs outstretched and head supported, the limbs being limp because the muscles are soft and the joints loose. The movements of its chest are characteristic of relaxed breathing, being quite slow and moderately shallow with a pause at the end of every expiratory phase. This is a picture of subconscious relaxation. The patient who is habitually tense has to practice relaxation consciously before it becomes a habit-a part of himself.

Initially he needs help directed toward developing muscle awareness, so that he can appreciate muscle activity in its minor degrees, and then be able to relax it completely. Thus he can be certain for himself if - he has or has not relaxed his muscles when he is supported in the correct position.

\section{Muscle Activity.}

Understanding and appreciation of muscle activity go hand in hand. Muscles work to maintain a position, that is to prevent movement. The most obvious illustration of this is the ordinary standing position, the smallest possible area of the body would cause it to collapse in a heap on the floor if it were not for the muscles supporting the ankles, knees, hips and spinal joints which hold the body upright. The effort is minimal and subconscious or reflex. This can only be appreciated if it is understood. Again any movement however large or small, is the result of muscle activity, and this too, more often than not, is subconscious. Gesticulating, changes in facial expression, drumming with a little fingerall are examples of outward and physical expressions of inner mental activity to the level of awareness, by drawing attention to it, by doing and feeling it, and then allowing it all to cease. It involves simple active movements through which the patient understands when a muscle is shortening, or lengthening, or holding a position. During the movement the patient is told when the working muscles are fixing the part or moving it or controlling the movement brought about by the weight of the part. When the distance to fall is harmless, the patient can learn to completely. release the muscle effort and allow the full weight of the part to bring it to rest.

These exercises are simplicity itself, but success for the patient may mean constant and lengthy repetition. However, once it is mastered, it will be as automatic as riding a bicycle eventually becomes. So long as the fundamental principles are applied, the patient will now find it easy to relax in any position in which the whole body weight is supported.

\section{Advanced Training.}

The more advanced relaxation exercises are harder to accomplish, for the patient is called upon to maintain his muscles in a relaxed state when disturbances are introduced. Disturbances, which, if allowed to produce a response would result in reflex muscle tension.

This is true conscious inhibition. The comfort of soft pillows is taken away, dim lighting is changed to normal day lighting, silent surroundings are altered to a certain amount of noise and movement in the room. The patient learns to make no response when touched or moved. He allows full range passive movements of his neck, arms and legs. He is asked to throw all the muscles of one limb into extreme tension and still maintain complete relaxation elsewhere, which can be demonstrated by passive movements. Later he learns to swing the emphasis in the opposite direction, so that all but one limb are tensed. It is indeed advanced relaxation to be able to inhibit localised muscle activity which so many other muscles are striving to reinforce through their own activity.

The practice of conscious inhibition is a state of selfdetachment from external and internal infuences of which the individual is fully aware.

Scheme of Relaxation Training.

The importance of a systematic scheme of relaxation training cannot be overstressed. The patient should be encouraged to practice for himself and be provided with something definite to do for home practice. Whether

(Continued on page 16.) 
Relaxation-Conscious Inhibition (Continued from page 14). it be to concentrate on the muscles which influence one particular joint and which he finds difficult to relax, or perhaps, simply to repeat the relaxation achieved at the previous treatment. The patient's aim should be to maintain the relaxation for a definite ten minutes adding a few minutes each day and working up to half an hour. This is the hardest exercise of all to many people, but it is of paramount importance and the most effective way of making muscle relaxation a habit to replace habitual muscle tension. Gradually the new habit is transferred to and put to every day use, less unnecessary muscular energy is expended whilst sitting at a desk at work, or standing or walking. Any opportunity should be taken if it offers a chance for some degree of relaxation. The busy housewife finding herself seated at some piece of work makes the most of the more restful position.

\section{Breathing Exercises.}

Deep breathing exercises are given by many physiotherapists to help patients to relax. They certainly have their place, but in the method described in this paper, no reference is made to respiration, except to point out that it is a continuous activity and that in the relaxed state it is quite characteristic and entirely automatic. During relaxation it becomes more evident to the patient because it is the only movement. Muscle activity disturbs the depth and rate of breathing in direct proportion. When the skeletal muscles are at rest the respiratory muscles respond to the controlling influence of the respiratory centre of the brain which functions in the resting state to ensure an adequate ventilation of the lungs.

\section{Conclusion.}

There is truth in the statement that a tense mind cannot exist in a relaxed body. The state of the mind influences the muscles too, but the practice of physical relaxation will help to relieve mental tension. In this way the physiotherapist is able to relieve patients who suffer from muscle tension caused by a physical disability, and patients who suffer from mental tension causing symptoms of physical tension.

Everyone will find that half an hour's complete relaxation before participating in strenuous mental and physical activities has a beneficial effect in combating anxiety and fatigue. It is, in fact, a practice common amongst famous men and women in the worlds of politics, drama and sport.

\section{ETHICAL RULES FOR MEMBERS OF THE S.A. SOCIETY OF PHYSIOTHERAPY.}

1. Not to undertake the treatment of any patient, except when referred by a registered medical practitioner.

2. Not to sell goods to a patient in a professional capacity, nor to accept commission on the sale of goods.

3. Not to pay a commission or give any valuable consideration for the introduction of patients.

4. Not to advertise, except in recognised medical publications.

5. Not to influence a patient for the purpose of effecting a change of medical adviser.

6. Not to conduct oneself in such a way as to bring discredit on the profession.

7. At all times to conduct oneself so as to ensure a proper respect for the interests of the patient, proper discharge of duty to the public, and to preserve mutual confidence and dignity within the profession.

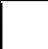 \\ SOUTH AFRICAN SOCIETY OF PHYSIOTHERAPY. GROUP ENDOWMENT FUND}

We have pleasure in announcing that a Group Endowment Fund has been inaugurated for members of the South African Society of Physiotherapy and will be underwritten by The Colonial Mutual Life Assurance Society Limited (hereinafter referred to as the Underwriters).

The Fund will enable members of the Society to obtain assurance at a lower cost than is possible with individual contracts and will enable them not only to insure their lives for the benefit of their dependents but to save for their retirement by deduction of regular monthly contributions from salary.

Members of the Society who wish to insure under this scheme must complete a short Proposal Form together with a Stop Order for the deduction of contributions monthly from salary.

The Trustees of the Fund will hold at the Society's headquarters a master policy on the schedules of which wilt be entered full particulars of each member's assurance.

The benefits consist of guaranteed amounts payable at the age selected by the member, or on prior death, and are subject to increase by annual bonus additions. Additional benefits in the form of Cash Payments subject to increase by bonus additions as declared in the Underwriter's Accident Department and waiver of future contributions are payable upon disablement due to certain contingencies prior to the selected age as set out on the master policy.

\section{BENEFITS WILL DEPEND UPON:}

(1) The member's age on entry into the scheme;

(2) The monthly contribution to be paid;

(3) The selected age at which the sum assured is payable.

ALL MEMBERS WILL RECEIVE A CERTIFICATE OF ENROLMENT GIVING FULL DETAILS OF CONTRIBUTIONS AND BENEFITS.

In the event of a member leaving the Society, the enrolment will be converted into an ordinary policy with the underwriters. Benefits and contributions will remain unchanged but future Bentributions will require to be paid direct to the underwriters. contributions will require to be paid direet to the underwriters. circumstances, be converted into a policy on the life of her husband if he is insurable and not more than 10 years her senior

The Fund is similar to that which has operated for the benefit of members of the South African Nursing Association for many years and the Executive of your Society hope that all members will give the Fund their full support.

\section{CUT IIERE.}

To the TRUSTEES GROUP ENDOWMENT FUND, S.A. SOCIETY OF PHYSIOTHERAPY, P.O. BOX 1106, PRETORIA.

Please supply me with details.

Name.

Address

Date of Birth

Where employed.

How much can you afford to pay each month: 